\title{
Pengenalan Potensi, Pariwisata dan Budaya Kabupaten Brebes Berbasis Android Menggunakan Metode Disciplined Agile Delivery
}

\author{
Merry Shovita Rizkiana ${ }^{\# 1}$, Fahrudin Mukti W \#2, Yudha Saintika \#3 \\ \# Institut Teknologi Telkom Purwokerto \\ Jl. D. I Panjaitan No. 128 Purwokerto, Jawa tengah \\ ${ }^{1} 15102104 @$ ittelkom-pwt.ac.id \\ ${ }^{2}$ fahrudin@ittelkom-pwt.ac.id \\ 3yudha@ittelkom-pwt.ac.id
}

Accepted on 19-05-2020

\begin{abstract}
Abstrak
Keragaman potensi alam serta tradisi budaya di Indonesia menjadi kekayaan yang perlu kenal dan dilestarikan. Salah satu ragam budaya yang masih terjaga hingga kini terdapat di Kabupaten Brebes yaitu Tradisi Jalawastu. Selain keragaman dari segi budaya, Kabupaten Brebes juga memiliki potensi lain yaitu, pariwisata alam, peninggalan sejarah yang masih dilestarikan. Dari ragamnya kekayaan tersebut diperlukan sarana informasi yang memadai agar dapat memudahkan masyarakat luas dalam mengenal celah Indonesia khususnya di Kabupaten Brebes yang masih minim. Upaya yang dilakukan untuk memperkenalkan hal tersebut adalah membuatkan wadah untuk menampung informasi tersebut. teknologi berbasis android mobile dipilih sebagai inovasi untuk mengenalkan keragaman potensi serta budaya dengan cara yang lebih efisien dan simpel. Untuk membuat aplikasi ini diperlukannya juga metode yang dapat membuat sistem ini dapat dikerjakan dengan secara runtutan waktu yang tepat, sehingga sistem ini dapat digunakan oleh seluruh masyarakat serta para wisatawan.
\end{abstract}

Kata kunci: Android, Brebes, DAD, Jalawastu, Pariwisata

\section{PENDAhuluan}

B rebes merupakan sebuah kabupaten di Jawa Tengah yang memiliki luas wilayah hingga 1.662,96 km² yang terdiri atas 17 kecamatan serta kelurahan atau desa sebanyak 297 yang tersebar di wilayah pantai, dataran rendah hingga dataran tinggi ini membuat Kabupaten Brebes memiliki daya tarik wisata alam dan budaya yang melimpah [2]. Kekayaan budaya dan pariwisata di Kabupaten Brebes masih jarang diketahui oleh kebanyakan orang, padahal jika diteliti lebih dalam, Brebes tidak hanya terdapat banyak unsur pariwisatanya saja, budaya dan adat yang dimiliki juga kental dan masih dijaga hingga sekarang. Begitu juga dengan potensi alam yang dapat dimanfaatkan oleh warga sekitar. Pemanfaatan kekayaan tersebut membuat para warga menjadi kreatif dan membuat semacam UKM atau Usaha Kecil Menengah di daerah asalnya. 
Salah satu cara dalam upaya untuk memperkenalkan potensi-potensi tersebut dapat melalui internet atau dengan aplikasi mobile [3].

Jika dilihat dari perkembangan pengunjung, Kabupaten Brebes dari tahun 2011-2015 mengalami kenaikan yang baik. Kenaikan ini menjadi sebuah peluang untuk lebih mengenalkan mengenai Kabupaten Brebes agar semakin meluas. Data kenaikan pengunjung Kabupaten Brebes pada tahun 2011 hingga 2015 ditunjukkan pada Gambar 1.1.

\begin{tabular}{cccc}
\hline \hline \multirow{2}{*}{$\begin{array}{c}\text { Tahun } \\
\text { Year }\end{array}$} & \multicolumn{2}{c}{$\begin{array}{c}\text { Wisatawan } \\
\text { Visitors }\end{array}$} & $\begin{array}{c}\text { Jumlah } \\
\text { Total }\end{array}$ \\
\cline { 2 - 3 } & $\begin{array}{c}\text { Mancanegara } \\
\text { International }\end{array}$ & $\begin{array}{c}\text { Domestic } \\
\text { Domestic }\end{array}$ & \\
\hline$(1)$ & $(2)$ & $(3)$ & $(4)$ \\
\hline & & 222688 & 222688 \\
2011 & - & 249365 & 249365 \\
2012 & - & 262676 & 262676 \\
2013 & - & 315477 & 315477 \\
2015 & - & 396714 & 396714 \\
\hline \hline
\end{tabular}

Gambar 1.1 Data kenaikan pengunjung tahun 2012-2015

Memiliki kekayaan alam yang dekat dengan pantai, pegunungan, membuat para warga Kabupaten brebes dapat berkreasi dengan mengolah kekayaan yang ada hingga terbentuklah banyak sekali UKM yang ada di kabupaten Brebes ini. Salah satu khas dari daerah Brebes ini adalah telor asin serta kerajinan rebana, serta Kota Brebes juga dikenal dengan petani bawang merahnya dan disebut juga kota Bawang [5]. Selain kekayaan dari segi kreatifitas UKM, Kota Brebes juga memiliki kekayaan seni budaya, tradisi yang masih dijaga hingga saat ini, diantaranya yaitu Gelar Tradisi Jalawastu, Panenambah Angka Wijaya Losari, Sedekah Laut Malahayu, dan lain-lain. Tradisi tersebut masih dilakukan hingga sekarang, serta penjagaan situs kebudayaan yang berupa bangunan maupun lainnya juga masih ada di Kabupaten Brebes, seperti Situs Gunung pojok Tilu, Bendung Dandang Gondang, Candi Pakuan, dan masih banyak lagi [5]. Dari banyaknya potensi, pariwisata dan budaya yang ada, telah dikembangkan oleh beberapa developer untuk membuat aplikasi mengenai Kabupaten Brebes ini. Namun, pengenalan ini tertuju hanya pada wisata saja.

Salah satu Metode dalam pengembangan perangkat lunak adalah metode DAD atau Disciplined Agile Delivery yaitu metode yang terbentuk dari best practices dari perangkat lunak dari jenis agile lainnya, seperti SCRUM, XP, Agile Modeling, Lean dan lainnya. Metode ini digunakan untuk menjadi acuan dalam membangun aplikasi mobile mulai dari tahapan pengumpulan data hingga aplikasi rilis. Aplikasi mobile itu sendiri merupakan sebuah aplikasi yang digunakan pada perangkat telepon genggam pintar atau smartphone dengan cara mengunduh atau download pada layanan pembelian aplikasi yang tersedia, misalnya AppStore, Playstore, dan Googleplay. Cara penyajian serta tampilan yang mudah digunakan dan dimengerti membuat aplikasi mobile ini lebih mudah untuk diterima masyarakat [4].

Pada penelitian ini akan merancang sebuah aplikasi Android dengan tema "Pengenalan Potensi, Pariwisata dan Budaya Kabupaten Brebes Berbasis Android Menggunakan Metode Disciplined Agile Delivery (DAD)". Menurut jurnal yang berjudul "Perancangan Aplikasi Monitoring Pemadaman Listrik Berbasis Android Studi Kasus PT.PLN Area Manado", metode Disciplined Agile Delivery atau DAD dapat digunakan untuk mengembangkan sebuah aplikasi untuk memudahkan masyarakat Kota Manado agar mendapatkan informasi mengenai pemadaman Listrik dan gangguan dari PT. PLN Area Manado. Dari hasil penelitian tersebut disimpulkan bahwa penggunaan metode DAD dapat berjalan baik sesuai dengan rencana serta kebutuhan [6]. Selain itu, menurut jurnal lain berjudul "Perancangan Sistem Informasi Pemetaan dan Pemantauan Daerah Aliran Sungai (DAS) Tondano di Kota Manado berbasis SMS-Gateway", metode DAD ini digunakan sebagai panduan pengembangan sistem informasi untuk pemetaan dan pemantauan DAS Tondano dapat terselesaikan 
dalam waktu yang relatif singkat [7]. Oleh sebab itu, penulis menggunakan metode Disciplined Agile Delivery sebagai langkah pengerjaan serta pengembangan. Penggunaan metode ini dipilih sebagai langkah awal untuk memulai sebuah proyek, membangun solusi serta memproduksi sebuah sistem itu sendiri dengan baik dan relatif singkat. Dengan adanya rancangan aplikasi ini diharapkan Kabupaten Brebes dapat dikenal lebih luas oleh wisatawan lokal maupun mancanegara baik dari segi potensi, pariwisata serta budayanya.

\section{TINJAUAN PUSTAKA}

Dalam penelitian-penelitian sebelumnya, penggunaan aplikasi mobile berbasis Android sudah banyak dilakukan guna untuk mempermudah suatu pekerjaan maupun memberikan informasi. Untuk mempermudah dalam proses pembuatan sistem berbasis android, metode yang digunakan yaitu Disciplined Agile Delivery sebagai acuan langkah dalam membangun sistem. Selain itu, sebagai penguat penulis untuk membuat penelitian, terdapat beberapa jurnal penelitian terdahulu untuk dijadikan referensi. Adapun jurnal terkait yang digunakan yaitu:

1) Rancang Bangun Aplikasi Pemesanan Tiket Online Kapal Laut Berbasis Android., Deybi W.E. Sede,

Alicia A. E. Sinsuw dan Xaverius B. N. Najoan., E-Journal Teknik Informatika 2015 [8]

Penelitian yang dilakukan yaitu membangun sebuah sistem informasi pemesanan tiket online kapal laut yang akan berlayar di seputaran Nusa Utara. Adapun fitur aplikasi yang dibangun dengan berbasis Android ini berisikan tentang jadwal kapal, cek tiket, booking tiket dan mendaftar sebagai member. Perancangan dalam pembuatan sistem informasi ini menggunakan metode Disciplined Agile Delivery sehingga sistem informasi tersebut dapat sesuai dengan keperluan sistem. Dalam hal ini, persamaan yang dimiliki adalah pengimplementasian pada sistem informasi Android serta metode yang digunakan. Sehingga dapat dijadikan studi literatur oleh penulis untuk penelitian yang sedang berlangsung.

2) Rancang Bangun Aplikasi "Trip Alone?" Berbasis Android., Kelvin Wong, Alicia A.E. Sinsuw dan

Xaverius B.N. Najoan., E-journal Teknik Informatika 2016 [9]

Penelitian yang dilakukan yaitu membangun sebuah aplikasi berbasis Android yang digunakan untuk mewadahi atau menampung para wisatawan untuk pergi berlibur, mencari teman trip atau pencari biro perjalanan. Adapun fitur yang disediakan yaitu melihat daftar trip, manajemen trip, melihat profil dan mencari trip. Metode yang digunakan dalam pembuatan aplikasi ini adalah DisciplinedAgile Delivery atau DAD karena peneliti merasa bahwa metode ini dapat memenuhi kebutuhan pengguna secara tepat dan dapat diselesaikan dengan waktu yang relatif singkat. Dalam hal ini, persamaan yang dimiliki adalah metode yang digunakan. Serta pengimplementasiannya pada perangkat Android. Tema yang dimiliki hampir sama, mengenalkan tentang pariwisata di daerah tertentu namun penulis lebih memperdalam kekayaan yang ada, sedangkan pada peneliti sebelumnya lebih untuk menyediakan jasa pariwisata.

3) Aplikasi Pembelajaran Sejarah Filsafat Berbasis Android Menggunakan Metode Pengembangan Agile., Eka Prasetya Adhy Sugara, Angger Perdana dan Anton Subrata., Seminar Nasional Teknologi Informasi,

Bisnis dan Desain 2017 [10]

Penelitian yang dilakukan yaitu membuat sebuah aplikasi berbasis Android yang bertujuan untuk dijadikan solusi pembelajaran pada mata kuliah Sejarah Filsafat dengan media yang lebih praktis untuk dipelajari dimana saja dan kapan saja. Serta dikemas dalam bentuk aplikasi agar yang dapat menampilkan animasi, video dan suara sehingga lebih menarik dalam penyampaian materi. Adapun fitur yang terdapat pada aplikasi ini yaitu menu utama, menu "Sejarah Filsafat", menu "Filosofi Yunani Kuno", menu "Filsuf Modern" dan about. Metode yang digunakan masih sama dari pengembang Agile namun dengan model RUP atau Rational Unified Process. Dalam hal ini, persamaan yang dimiliki adalah sama-sama menggunakan Android sebagai sistem informasi yang digunakan, namun menggunakan model yang berbeda dari sebuah metode yang sama yaitu Agile Development.

4) Perancangan Aplikasi Monitoring Pemadaman Listrik Berbasis Android Studi Kasus PT.PLN Area Manado., Harnolus koyuko, Alicia A. E. Sinsuw, Xaverius B. N. Najoan., E-journal Teknik Informatika $2016[6]$ 
Penelitian yang dilakukan yaitu membuat sebuah aplikasi berbasis Android yang digunakan sebagai media untuk memudahkan masyarakat atau pengguna listrik yang dikelola oleh PT.PLN untuk mendapatkan informasi mengenai pemadaman listrik memberikan pelaporan mengenai gangguan yang terjadi agar dapat ditangani dengan cepat. Pembuatan ini disebabkan karena pertumbuhan perekonomian dan pemukiman yang terus meningkat mengakibatkan banyak permintaan daya yang harus dibagi, sehingga sering terjadi pemadaman listrik secara bergantian. Fitur yang terdapat pada aplikasi ini yaitu, pengguna dapat melihat info mengenai pemadaman serta pengguna dapat membuat pelaporan mengenai gangguan yang terjadi. Metode yang digunakan yaitu Disciplined Agile Delivery (DAD) sebagai metode perancangan sistem, sehingga aplikasi ini dapat terselesaikan sesuai dengan rencana dan kebutuhan. Persamaan jurnal diatas dengan penelitian yang dilakukan adalah pada penggunaan metode, yaitu Disciplined Agile Delivery (DAD) yang dapat membantu perancangan dalam pembuatan sistem agar dapat terselesaikan dengan baik.

5) E-Tourism Kota Tomohon Menggunakan HTML5., Harsda Mangkey, yaulie Rindengan, Virginia

Tulenan., E-journal Teknik Elektro dan Komputer 2016 [11]

Penelitian yang dilakukan adalah membuat sebuah sistem informasi berbasis website mengenai tempat wisata yang berada di daerah Tomohon, Sulawesi Utara. Alasan penelitian ini dilakukan selain memperkenalkan pariwisata di Tomohon adalah belum adanya website pariwisata yang menarik dengan tampilan yang tidak membosankan. Untuk itulah dibuat website menggunakan HTML5 untuk pembuatan antarmuka menarik serta penambahan fitur untuk menentukan kepuasan pengunjung. Dalam penelitian tersebut menggunakan metode Disciplined Agile Delivery (DAD) sebagai panduan proses dan aktivitas perancangan sistemnya sehingga dapat menghasilkan sebuah website sesuai dengan kebutuhannya. Persamaan penelitian penulis dengan jurnal diatas adalah dari penggunaan metode, yaitu Disciplined Agile Delivery (DAD). Perbedaannya hanyalah pada penerapan model sistem yang digunakan. Dari hasil penelitian tersebut dapat dijadikan referensi oleh penulis untuk kebutuhan penelitian yang dilakukan.

Disciplined Agile Delivery merupakan metode untuk merancang sebuah sistem informasi perangkat lunak berbasis Android. Metode ini digunakan karena dapat memenuhi kebutuhan pengguna dengan tepat dan jangka waktu yang digunakanpun cukup untuk memaksimalkan hasil dari penelitian ini sesuai dengan kelebihan metode DAD ini. Berikut ini adalah kunci yang menjadi aspek kelebihan dari metode DAD, antara lain:

1. Process Goal Driven

DAD menyarankan para peneliti untuk memilih sebuah strategi kerja sesuai dengan prioritas kebutuhan untuk stakeholder. Berbeda dengan SCRUM, yang termasuk dari Agile Development juga, namun pekerjaan diolah sesuai dengan antrian Backlog.

2. Full Delivery Lifecycle

Siklus hidup atau lifecycle dari metode DAD ini mengalamatkan seluruh projek dari sudut inisiasi hingga sampai pada kegiatan produksi dan setelah pembuatan projek tersebut. Hal ini berbeda dengan metode tangkas pada generasi pertama yang berfokus pada aspek-aspek pembangunan siklus hidup.

3. Solution Focused

Fokus dari metode DAD ini adalah untuk menghasilkan sebuah perangkat lunak atau software sebagai solusi yang dapat digunakan untuk masyarakat serta nilai bisnis bagi para pebisnis yang terkait. Metode DAD terdiri dari 3 fase pengembangan yaitu fase inception, fase construction, dan fase transition, yang ditunjukkan pada Gambar 2.1. 


\section{Disciplined Agile Delivery}

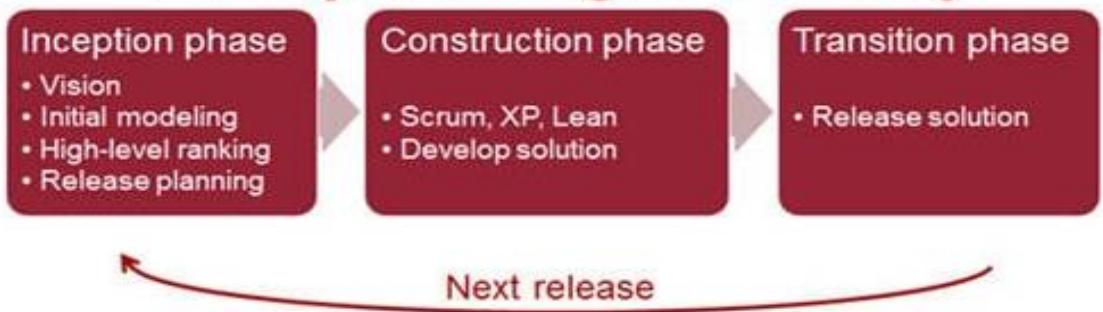

Gambar 2.1 Fase Metode Disciplined Agile Delivery

\section{Fase Inception}

Tahapan awal pada metode DAD ini adalah mengidentifikasi kebutuhan serta mengumpulkan data-data yang akan digunakan untuk mengembangkan sebuah sistem.

5. Fase Construction

Pada fase ini merupakan proses membangun aplikasi dengan penyesuaian berdasarkan kebutuhan dan fitur fitur yang telah ditentukan sebelumnya.

6. Fase Transition

Pada fase ini dilakukan review terhadap aplikasi yang telah kita bangun, pada bagain ini kan menjelaskan isi aplikasi dan cara menggunakan [9].

\section{METODE PENELITIAN}

Gambar 3.1 adalah diagram alir dalam melakukan penelitian ini. Penelitian dilakukan berdasarkan dengan metode DAD dengan tahapan sebagai berikut.

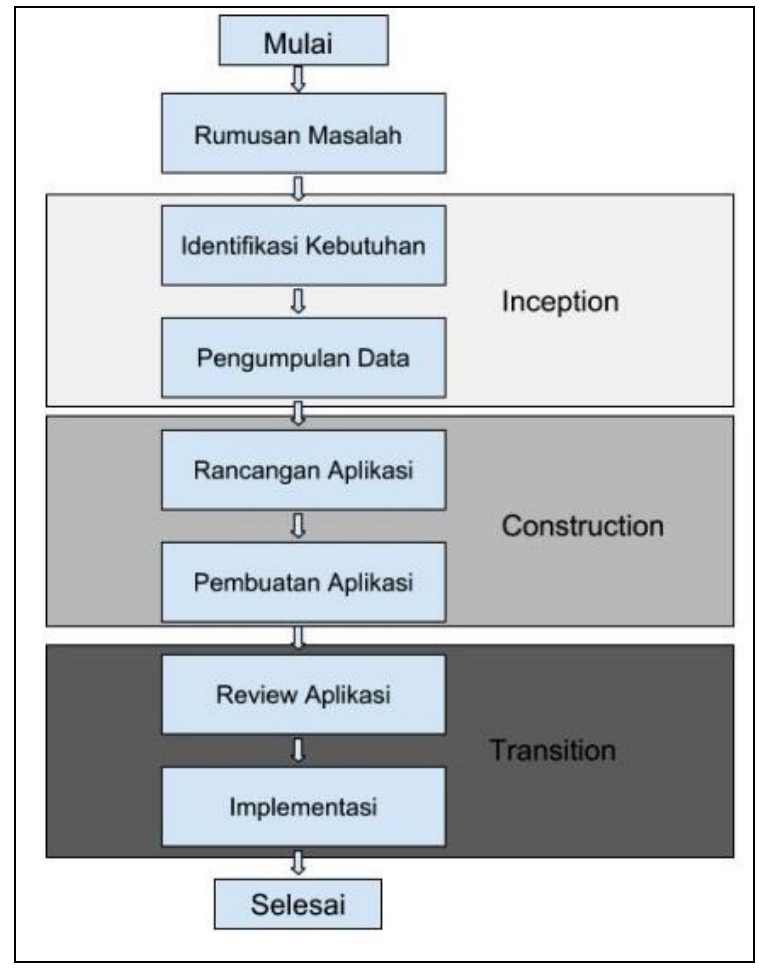

Gambar 3.1 Diagram Alir Penelitian 
Penelitian ini memiliki beberapa tahapan dengan dimulai dari merancang perumusan masalah dalam penelitian. Kemudian masuk kedalam 3 fase dalam metode DAD dengan setiap fase terdapat tahapan yang akan dikerjakan dalam penelitian. Dalam fase inception, tahapan nya yaitu terdapat 2 memulai dengan mengidentifikasi segala kebutuhan dalam merancang aplikasi ini dengan diklasifikasikan 2 jenis yaitu kebutuhan functional dan non-functional. Selanjutnya mengumpulkan data- data yang akan digunakan dan di tampilkan dalam aplikasi seperti dataset Kabupaten Brebes dan studi pustaka. Dalam fase construction, aplikasi mulai dirancang dengan membuat beberapa diagram yang digunakan seperti use case diagram, activity diagram, sequence diagram, dan class diagram. Tahap selanjutnya dalam fase interception yaitu membuat aplikasi atau melakukan pemrograman terhadap aplikasi. Memasuki fase ketiga yaitu transition, memiliki 2 tahapan yaitu review aplikasi. Dalam review aplikasi ini yang dimaksudkan yaitu pengujian terhadap seluruh fungsi dalam aplikasi. Tahapan selanjutnya yaitu implementasi yaitu aplikasi dapat bisa digunakan oleh masyarakat luas.

\section{HASIL DAN PEMBAHASAN}

Gambar 4.1 merupakan hasil tampilan dari aplikasi yang sudah dibangun dengan beberapa menu dan user interface dari aplikasi. Tampilan awal ketika aplikasi dibuka maka akan muncul sedikit pengenalan mengenai Kabupaten Brebes. Setelah itu ketika pengguna mengklik "Menu" maka tampilan akan masuk ke halaman menu.

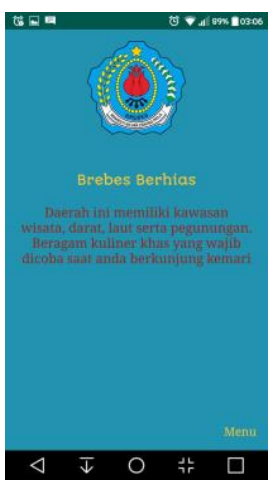

Gambar 4.1 Hasil Prototyping Intro

Menu ini berisikan 6 pilihan yang dapat dipilih oleh pengguna. Menu tersebut akan berisikan mengenai ragam Kabupaten Brebes. Gambar 4.2 merupakan implementasi dari rancangan yang dibuat.

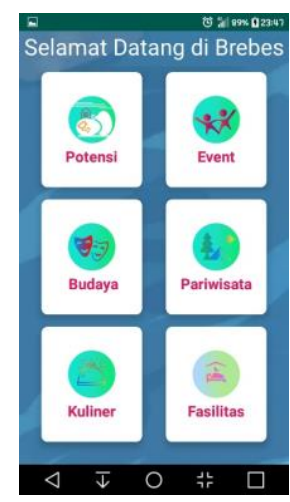

Gambar 4.2 Hasil Prototyping Menu

Semua desain yang dibuat untuk daftar menu adalah sama. Hanya saja kontennya yang berbeda. Berikut ini adalah implementasi dari rancangan desain untuk daftar menu. 


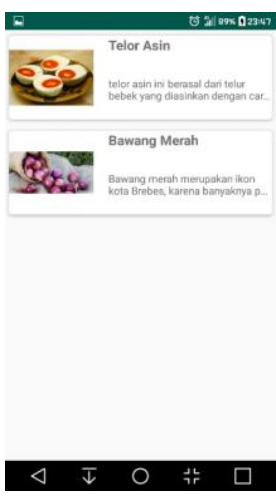

Gambar 4. 3 Hasil Prototyping List Menu

Sedikit perbedaan dari desain detail yang dibuat. Pada detail menu Potensi, Event, Budaya, Kuliner dan Hotel tidak ada informasi untuk menampung daftar Agen Travel. Berikut ini adalah gambar tersebut.

1) Detail Selain Pariwisata

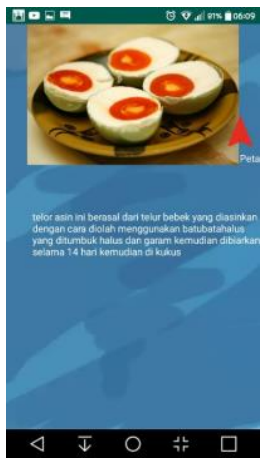

Gambar 4.4 Hasil Prototyping Detail Selain Pariwisata

2) Detail Pariwisata

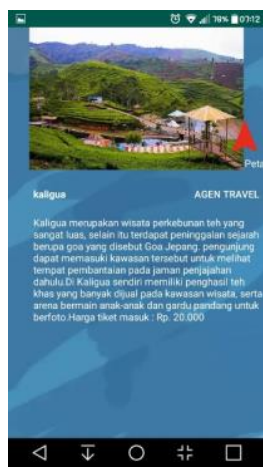

Gambar 4.5 Hasil Prototyping Detail Pariwisata

Hasil dari rancangan peta yang dibuat menghasilkan gambar seperti di bawah ini. 


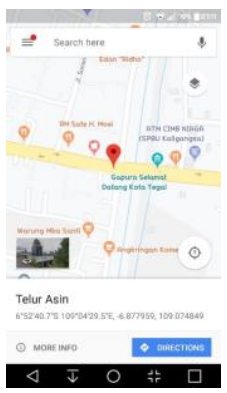

Gambar 4.6 Hasil Prototyping Peta

Agen travel ini dapat ditemukan pada detail menu pariwisata. Desain yang dibuat mengikuti dari rancangan sebelumnya. Hasil implementasi rancangan tersebut adalah sebagai berikut.

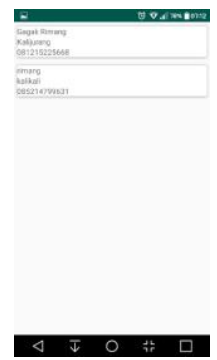

Gambar 4.7 Hasil Prototyping Agen Travel

\section{KESIMPULAN}

Dari hasil penelitian yang dilakukan oleh penulis untuk pembuatan aplikasi tentang Pengenalan Potensi, Budaya dan Pariwisata Kabupaten Brebes Berbasis Android Menggunakan Metode DAD atau Disciplined Agile Delivery, yaitu sebagai berikut:

1. Penggunaan metode DAD atau Disciplined Agile Delivery untuk membangun sistem aplikasi Brebes-ku ini dinilai sesuai, karena terstruktur dan sebagai pengembang awam dapat mudah mengikuti karena langkah-langkah pembuatan yang jelas.

2. Berdasarkan kuisioner dan pengujian sistem kepada pengguna, aplikasi ini dapat membantu mereka mengetaui potensi yang ada di Kabupaten Brebes

3. Berdasarkan pengujian black box semua fungsi dapat berjalan dengan baik

4. Versi android pada smartphone pengguna berpengaruh dalam menjalankan sistem ini

5. Aplikasi bersifat online, jika dijalankan tanpa jaringan internet maka gambar tidak dapat ditampilkan 


\section{DAFTAR PUSTAKA}

[1] G. P. R. Tegal, "Fosil dan Artefak di Bumiayu Diteliti Arkeolog Prancis," radartegal.com, 2018. [Online]. Available: https://radartegal.com/berita-lokal/fosil-dan-artefak-di-bumiayu-diteliti-arkeolog.22634.html. [Accessed: 13-Jan-2019].

[2] B. P. S. K. Brebes, Kabupaten Brebes dalam Angka. Brebes: BPS Kabupaten Brebes, 2016

[3] Afifuddin, "Pengembangan aplikasi," Univ. Islam Negeri Sunan Kalijaga, 2013.

[4] IDProgrammer, "Pengertian Mobile Web dan Mobile Aplikasi," 2017. [Online]. Available: https://idprogrammer.com/pengertianmobile-web-dan-mobile-aplikasi/.

[5] D. K. I. \& S. K. Brebes, Brebes. Brebes: Dinas Komunikasi Informatika dan Statistik Kabupaten Brebes, 2016.

[6] H. Koyuko, A. A. E. Sinsuw, X. B. N. Najoan, T. Informatika, U. Sam, and R. Manado, "Perancangan Aplikasi Monitoring Pemadaman Listrik Berbasis Android Studi kasus PT. PLN area Manado,” E-journal Tek. Inform., vol. 8, no. 1, pp. 1-11, 2001.

[7] P. Studi, T. Informatika, F. Teknik, U. S. Ratulangi, J. Kampus, and U. Bahu, "Perancangan Sistem Informasi Pemetaan Dan Pemantauan Daerah Aliran Sungai (DAS) Tondano Di Kota Manado Berbasis Sms-Gateway,” E-journal Tek. Inform., vol. 5, no. 1 , pp. 1-6, 2015.

[8] T. Informatika, U. Sam, and R. Manado, "Rancang Bangun Aplikasi Pemesanan Tiket Online Kapal Laut Berbasis Android," Ejournal Tek. Inform., vol. 1, no. 1, pp. 1-6, 2015.

[9] K. Wong et al., "Rancang Bangun Aplikasi ‘Trip Alone?’ Berbasis Android,” E-journal Tek. Inform., vol. 9, no. 1, pp. 1-7, 2016.

[10] S. Nasional et al., "Aplikasi Pembelajaran Sejarah Filsafat Berbasis Android," Semin. Nas. Teknol. Informasi, Bisnis dan Desain, pp. 1-6, 2017

[11] H. Mangkey, Y. Rindengan, S. T. M. M. M. Sc, V. Tulenan, S. K. M. Ti, and U. S. Ratulangi, "E-Tourism Kota Tomohon Menggunakan HTML5," E-Journal Tek. Elektro dan Komput., vol. 5, no. 4, 2016.

[12] R. Utama, I. G. Bagus, U. Dhyana, and P. Bali, "Kajian pariwisata dari perspektif ekonomi," Makal. Semin. Univ. Tabanan, Januari, 2017. 